\title{
Character Strengths and Ethical Engagement in Online Faculty
}

\author{
Justina $\operatorname{Or}^{1} \mathbb{D} \cdot$ Scott Greenberger ${ }^{1} \cdot$ Melissa A. Milliken ${ }^{1}$
}

Accepted: 23 June 2021 / Published online: 14 July 2021

(C) The Author(s), under exclusive licence to Springer Nature B.V. 2021

\begin{abstract}
In this study, the researchers investigated the relationships between character strengths and ethical engagement in online faculty. One of the ethical duties for higher education faculty is to engage in effective teaching practices. As online higher education becomes increasingly popular, online faculty also bear this duty. Numerous studies have shown that character strengths cultivate ethical behavior. Hence, we sought to determine the relationship between character strengths and ethical engagement in online faculty. Specifically, we focused on intellectual character strengths, interpersonal character strengths, and emotional character strengths because of their relevance to online faculty's teaching practices. Through correlational analyses, we learned that interpersonal and emotional character strengths were positively and moderately related to ethical engagement, whereas intellectual character strengths were weakly related to ethical engagement. The findings of this study provide insight into online faculty's character strengths and ethical engagement. However, further research is needed to understand the role of character strengths and ethical engagement in promoting effective teaching practices in online higher education classrooms.
\end{abstract}

Keywords Character strengths $\cdot$ Ethical engagement $\cdot$ Faculty ethics $\cdot$ Online faculty $\cdot$ Online teaching

\section{Introduction}

With the global COVID-19 pandemic, recent trends toward increased online higher education enrollments have continued (Wotto, 2020). Over the past 20 years, online higher education has transformed learning, producing unique online learning communities where learning collaboration and interaction can take place anywhere and anytime (Galikyan \&

Justina Or

justina.or@my.gcu.edu

Scott Greenberger

scott.greenberger2@gcu.edu

Melissa A. Milliken

melissa.milliken@gcu.edu

1 Grand Canyon University, 3300 W Camelback Rd, Phoenix, AZ 85017, USA 
Admiraal, 2019; Wang et al., 2017). Online faculty members' teaching practices such as classroom community building, course design, and discussion facilitation have significant influence on students' learning experiences (Ouyang \& Scharber, 2017). In examining effective teaching in online learning communities, Martin et al. (2019) found that essential characteristics of outstanding faculty teaching practices included thoughtful assessment design, timely feedback, availability, and periodic communication with students. Researchers have affirmed that students view these characteristics as helpful because they enhance the presence of the online instructor (Martin et al., 2018). However, in practice, faculty do not always demonstrate the essential characteristics of outstanding teaching behavior.

Faculty may sometimes engage in unethical and uncivil teaching approaches (Carrillo et al., 2019; McNeill et al., 2016). For instance, faculty may exhibit overly authoritarianbased behavior toward students, embed ideological bias into the course curriculum and grading process, and engage in acts of moral turpitude, such as teaching while intoxicated or starting inappropriate relationships with their students (Alt \& Itzkovich, 2015, 2019; Carrillo et al., 2019). Other faculty may offer students easier assignments and superfluous compliments to receive positive student evaluations, or, on the contrary, they could provide rude or inconsistent feedback and not be available to students (McNeill et al., 2016; Mohammadipour et al., 2018; Roberts, 2016). In a study exploring specifically online faculty uncivil behavior, McNeill et al. (2016) found that online faculty members demonstrated general rudeness, implemented unanticipated changes in course requirements, and gave students insufficient or untimely feedback. The online higher education classroom presents unique challenges due to its reliance on technology and limited synchronized interaction (Asamoah, 2019; Kebritchi et al., 2017).

Numerous sources have reported that unethical and uncivil behavior has had a negative influence on students and their learning (Alt \& Itzkovich, 2016; Mohammadipour et al., 2018). Some students who experienced faculty unethical or uncivil behavior reported feeling helpless, stressed, and dissatisfied with their program of study (Mohammadipour et al., 2018). Some students also reported experiencing a decline in academic performance (Alt \& Itzkovich, 2016; Mohammadipour et al., 2018). Effective teaching is strongly associated with positive learning outcomes (Symbaluk \& Howell, 2018). Therefore, faculty ethical behavior may be one of the primary factors affecting students' learning experiences and their academic success. "Ethics are an integral part of the teaching profession" (Aldosemani, 2020, p. 79). Faculty members' ethical behavior plays a crucial role in effective teaching (Ozcan et al., 2013). Those who demonstrate ethical behavior may be less likely to engage in unethical behavior and more likely to engage in effective teaching practices in the online classroom. However, that does not mean that ethical behavior cannot be developed consciously through training.

It is faculty's ethical duty to engage in effective teaching practices to cultivate meaningful learning experiences for students (Simpson, 2003). Ayers (2001) also stated, "the work of a teacher-exhausting, complex, idiosyncratic, never twice the same-is, at its heart, an intellectual and ethical enterprise" (p. 122). A high level of ethicality motivates faculty to use their best skills to engage in teaching-learning tasks (Sethy, 2018). To help faculty of all modalities to cultivate ethical behavior to fulfill part of their faculty role as teachers, universities and professional organizations have incorporated different strategies (Sethy, 2018). For instance, the American Association of University Professors (2009) published a statement on faculty ethics to guide the teaching practices of faculty members in the United States. Universities also compose codes of ethics, provide ethics training, and conduct ethics audits to ensure ethical behavior among faculty (Tauginiené, 2016). Another one of these strategies is the development of character strengths in faculty members. 
Character strengths refer to positive individual traits that describe virtuous character, as they manifest into one's thoughts, feelings, and actions (McGrath, 2015b; Peterson \& Seligman, 2004). Character strengths have been shown to be effective tools faculty members can employ to engage in ethical and effective teaching practices (McGovern, 2011; McGovern \& Miller, 2008). For instance, the character strengths, curiosity and love of learning, enable faculty to explore innovative learning and teaching processes and continue to build on their existing knowledge systematically (McGovern, 2011). Faculty may also employ the character strengths, kindness and love, to capitalize the diversity among students ethically and create a safe space that cultivates supportive and respectful relationships (McGovern \& Miller, 2008). Another example is the employment of self-regulation, which allows faculty to control their initial responses to difficult classroom situations and weigh different options before implementing the most appropriate one (McGovern, 2011). Lastly, faculty may use the character strength, zest, to demonstrate enthusiasm when teaching (McGovern \& Miller, 2008). Given the rising popularity of online higher education, its unique challenges, and its prevalence, there is a need to study online faculty ethical behavior. Therefore, in the present study, the researchers examined the relationship between character strengths and ethics in online faculty.

\section{Ethics and Character Strengths}

\section{Ethics in Higher Education}

Ethics are moral principles that outline what is right and wrong and govern one's behavior (Plante \& McCreadie, 2019a). In higher education, ethics often entail academic ethics, which generally refer to the standards and behavior required in the academic setting to promote integrity in educational practices (Asamoah, 2019). Researchers have studied academic ethics from a variety of angles. For instance, Bretag and Green (2014) explored the ethical behavior of academic leaders in an Australian university and found that virtue ethics principles were often used in relation to academic integrity policies among these academic leaders. Another scholar explored Finnish universities' adherence to national ethical guidelines on plagiarism by analyzing those universities' reactions to notifications of suspected plagiarism (Moore, 2020). The findings revealed the universities had many inconsistencies in regard to the definition of plagiarism and disciplinary actions against plagiarism (Moore, 2020). Other researchers have examined academic ethics regarding scientific misconduct among researchers (Tagne et al., 2020). One of the key findings was that the participants of the study were concerned with the volume of misconduct (Tagne et al., 2020). Academic honesty, unethical behavior intention, and ethical reasoning abilities have also been points of emphasis in academic ethics research (Henning et al., 2020; Jamil et al., 2019; Pau et al., 2019). These different points of emphasis are useful in understanding the variety of ways in which ethical behavior may manifest in the academic setting.

\section{Ethical Engagement}

Ethical engagement is another effective way to assess the ethical behavior of different university populations, including online faculty members (Plante \& McCreadie, 2019a; Plante $\&$ Plante, 2017). Plante and McCreadie (2019a) defined ethical engagement as one's interest and engagement in ethical issues. Such ethical engagement is both internal and external 
(Plante, 2004). In other words, it takes place in the form of thoughts and feelings, as well as overt actions. When individuals have a high level of ethical engagement, they are generally involved with ethical issues and behave ethically in a consistent manner. A high level of ethical engagement in online faculty will likely translate into ethical behavior in their teaching work.

Plante and McCreadie (2019a) created the Santa Clara Ethics Scale (SCES) to measure the degree of ethical engagement. This instrument has 10 items. The highest score for each item is four, whereas the lowest score for each item is one. The SCES produces a summed score based on the scores of all the 10 items for ethical engagement. The maximum score one may receive from the SCES is 40, and the minimum score one may receive from the SCES is 10. A high score reflects a high level of ethical engagement, which means the individual is interested and engaged in ethical issues, and vice versa. Respect, responsibility, integrity, competence, and concern for others are the values highlighted in the SCES (Plante \& McCreadie, 2019a).

To examine the new scale's validity and reliability, Plante and McCreadie (2019a) tested the SCES using 200 participants. The researchers performed factor analysis and showed that ethical engagement accounted for $42 \%$ of the variability in all 10 variables of the scale, supporting the test's validity. The SCES also has a Cronbach's alpha of $>0.83$, which indicates reliability. Plante and McCreadie (2019b) conducted another study on the SCES. This study also supported the validity and reliability of the SCES. Not only is the SCES valid and reliable, but it is also particularly effective compared with other available ethics measures. It is user-friendly because it has only 10 items and uses concise language (Plante \& McCreadie, 2019b). Because the contents of the items are general, the scale can be used for a variety of purposes (Plante \& McCreadie, 2019b). Plante and McCreadie (2019a) recommended future research be conducted with different university populations.

\section{Character Strengths}

According to Peterson and Seligman (2004), there are 24 character strengths. These character strengths are positive psychological mechanisms that define the six virtues needed for virtuous character. Peterson and Seligman's (2004) character strengths model is rooted in Aristotle's virtue ethics - a normative ethics theory that places an emphasis on virtue and character. Aristotle believed virtues are expressed through one's behavior and can help individuals to become ethical exemplars when they are practiced consistently (Bretag \& Green, 2014; Ghosh, 2016). Like the six virtues, character strengths make individuals who possess and consistently practice them virtuous agents (Peterson \& Seligman, 2004).

Peterson and Seligman (2004) identified six universal virtues through philosophical, historical, and cross-cultural analyses. These virtues are wisdom, courage, humanity, justice, temperance, and transcendence. To describe the six virtues in greater detail, Peterson and Seligman identified 24 different positive psychological processes, known as character strengths. These 24 character strengths manifest in one's behavior through thoughts, feelings, and actions (McGrath, 2015b; Peterson \& Seligman, 2004). They also tend to be consistent across situations and time (Höfer et al., 2020; Peterson \& Seligman, 2004). Because character strengths are behavioral dispositions that represent virtuous character, they offer opportunities for the empirical investigation of normative ethics (Crossan et al., 2013). As shown in Table 1, each of the 24 character strengths represents one of the six virtues (Peterson \& Seligman, 2004). 
Table 1 Character Strengths and Virtues

\begin{tabular}{ll}
\hline Virtue & Character Strength \\
\hline Wisdom & Creativity, curiosity, open-mindedness, love of learning, perspective \\
Courage & Bravery, perseverance, integrity, zest \\
Humanity & Love, kindness, social intelligence \\
Justice & Teamwork, fairness, leadership \\
Temperance & Forgiveness, humility, prudence, self-regulation \\
Transcendence & Appreciation of beauty and excellence, gratitude, hope, humor, \\
& spirituality \\
\hline
\end{tabular}

Source: Peterson and Seligman (2004)

Research shows character strengths are linked to ethics indicators. In a study conducted by Or (2020), character strengths of courage and humanity were found to be positively and moderately correlated with ethical engagement in human services professionals. Other recent studies concerning character strengths and ethics primarily pertain to the relationship between leader characteristics and ethical leadership (Eisenschmidt et al., 2019; Palanski et al., 2015; Sosik et al., 2019; Thun \& Kelloway, 2011). Sosik et al. (2019) examined the relationship between character strengths, ethical leadership, leadership performance, and psychological wellbeing. They demonstrated that when military officers possessed a high level of self-regulation, their integrity, social intelligence, and bravery manifested in their ethical leadership, in-role performance, and psychological wellbeing. Palanski et al. (2015) found that courage explained the relationship between ethical decision-making and integrity and work performance in leaders across a variety of sectors in the United States.

Another similar study examining the relationship between character strengths and ethical leadership revealed subordinates who reported higher levels of character strengths demonstrated by their supervisors also reported high levels of ethical leadership and lower levels of abusive supervision demonstrated by their supervisors (Thun \& Kelloway, 2011). In a qualitative study, Eisenschmidt et al. (2019) interviewed several exemplary principals in Estonia and Finland to find out how the six virtues may create purpose for ethical leadership. The principals discussed the ways the virtues had informed their resolutions of different work challenges. All the six virtues played a role in creating purpose for ethical leadership in principals, although wisdom, courage, and humanity were the most commonly displayed virtues in their resolutions (Eisenschmidt et al., 2019). In these three virtues, love of learning, social intelligence, and bravery were the most notable character strengths. The findings of this study also suggest the character strengths model is a suitable comprehensive framework for educational contexts (Eisenschmidt et al., 2019).

Character strengths can also be categorized based on a five-factor classification (MartínezMartí \& Ruch, 2017; Peterson \& Seligman, 2004). As described in Table 2, these five classifications include restraint strengths, intellectual strengths, interpersonal strengths, emotional strengths, and theological strengths. Because Peterson and Seligman's original six-virtue classification is generally considered theoretical, some researchers have opted for this fivefactor classification of character strengths when researching character strengths (Harzer \& Ruch, 2015; Martínez-Martí \& Ruch, 2017; Najderska \& Cieciuch, 2018; Peterson \& Seligman, 2004).

The Value in Action Inventory of Strengths (VIA-IS) is the most common assessment used to measure the degree of one's character strengths (McGrath, 2015a). The VIA-IS is the full version of the test, which consists of 240 items. It intends to produce separate 
Table 2 Five-factor Classification of Character Strengths

\begin{tabular}{ll}
\hline Factor & Character Strengths \\
\hline $\begin{array}{l}\text { Restraint strengths } \\
\text { Intellectual strengths }\end{array}$ & $\begin{array}{l}\text { Fairness, humility, forgiveness, prudence } \\
\text { Creativity, curiosity, love of learning, appre- } \\
\text { ciation of beauty and excellence }\end{array}$ \\
$\begin{array}{l}\text { Interpersonal strengths } \\
\text { Kindness, love, leadership, teamwork, humor } \\
\text { Theological strengths }\end{array}$ & $\begin{array}{l}\text { Bravery, hope, self-regulation, zest } \\
\text { Gratitude, spirituality }\end{array}$ \\
\hline
\end{tabular}

Source: Peterson and Seligman (2004)

scores for the 24 character strengths and the classifications of character strengths (including the six-virtue classification and five-factor classification). As the scale became more popular, Peterson and Seligman (2004) developed shorter versions for the VIA-IS to make the scale more accessible and user-friendly, including the VIA-72 (which has 72 items). The VIA-72 has validity coefficients ranging from 0.36 to 0.48 , which indicates validity, and a Cronbach's alpha of $>.70$, which indicates reliability (Peterson \& Seligman, 2004). Researchers indicated there is a need to examine the relationships between character strengths and different ethics indicators to determine if character strengths are associated with ethics development as theorized (Han, 2019).

\section{Ethical Engagement, Character Strengths, and Online Teaching}

Effective teaching is part of being an ethical faculty member (Corlett, 2014). With a higher level of ethical engagement, online faculty members are more motivated to perform at their best and more likely to engage in effective teaching practices (Sethy, 2018). Character strengths support individuals in becoming ethical agents, therefore, they can serve as effective tools for promoting ethical behavior of online faculty (McGovern, 2011; McGovern \& Miller, 2008). Since character strengths are generally manifested in one's behavior consistently across situations, they also serve as predispositions for effective teaching practices (McGovern, 2011; McGovern \& Miller, 2008; McGrath, 2015b). Symbaluk and Howell (2018) found there to be relationships between faculty's character strengths and outstanding teaching practices as rated by students. The findings revealed the character strengths, perspective, kindness, leadership, humor, creativity, zest, and fairness, to be the most observed traits by students among these members who engaged in highly regarded teaching practices. The findings suggest these strengths are linked to enhanced teaching performance of faculty members.

Scholars agree that the work of a teacher involves the use of intellectual, interpersonal, and emotional skills (Ayers, 2001; McGovern, 2012; Symbaluk \& Howell, 2018). Thus, some types of character strengths from Peterson and Seligman's (2004) five-factor classification, such as intellectual, interpersonal, and emotional strengths, can be especially useful tools for meeting the unique challenges of online instruction. Intellectual strengths (which include creativity, curiosity, love of learning, and appreciation of beauty and excellence) refer to one's enthusiasm for creativity (Duan \& Ho, 2018). They facilitate problemsolving and knowledge acquisition (Harzer \& Ruch, 2015). Interpersonal strengths (which include kindness, love, leadership, teamwork, and humor) involve one's love, concern for others, and gratitude (Duan \& Ho, 2018). They help individuals handle social interactions positively and sustain relationships with others (Harzer \& Ruch, 2015). Emotional 
strengths (which include bravery, hope, self-regulation, and zest) concern responding to emotional experience in a vulnerable way (Peterson \& Seligman, 2004). This quality enables individuals to use positive coping strategies under stress (Harzer \& Ruch, 2015).

Intellectual, interpersonal, and emotional strengths are relevant to online faculty's teaching practices. Online faculty members may use intellectual strengths to facilitate student learning innovatively, expand their knowledge about online teaching best practices, pursue new ideas systematically, and recognize the talents of their students (McGovern \& Miller, 2008). The use of interpersonal strengths promotes the development of a safe learning environment that fosters trusting relationships among faculty and students (Tsui \& Ngo, 2016). It also helps online faculty skillfully facilitate student collaboration and fulfillment of classroom tasks (McGovern, 2011). Finally, online faculty members with emotional strengths are more likely to manage the demands of online teaching effectively and positively; they demonstrate a passion for teaching and self-control in different classroom situations (McGovern, 2011; McGovern \& Miller, 2008).

There is a need to examine online faculty ethical behavior in the prevalence of online higher education, as well as character strengths which are theorized to improve faculty's ethical behavior and teaching practices. Scholars have also recommended further research on the SCES with different university populations and the relationships between character strengths and ethics indicators (Han, 2019; Plante \& McCreadie, 2019a). Based on these recommendations, the study emerged with a focus on the correlations between character strengths and ethical engagement in online faculty. As intellectual, interpersonal, and emotional strengths are important to the teaching practices of online faculty, the examination of the relationships between character strengths and ethical engagement in online faculty warrants a focus on these strengths. In this study, the researchers formulated the following questions:

Research Question 1: Is there a positive relationship between intellectual strengths (creativity, curiosity, love of learning, and appreciation of beauty and excellence) and ethical engagement in online higher education faculty?

Research Question 2: Is there a positive relationship between interpersonal strengths (kindness, love, leadership, teamwork, and humor) and ethical engagement in online higher education faculty?

Research Question 3: Is there a positive relationship between emotional strengths (bravery, hope, self-regulation, and zest) and ethical engagement in online higher education faculty?

\section{Research Methods}

\section{Population and Sampling}

After IRB approval was obtained, the researchers administered a survey to online faculty members at a 4-year university in Arizona to test the relationships between character strengths (intellectual strengths, interpersonal strengths, and emotional strengths) and ethical engagement in online higher education faculty. The survey included items measuring character strengths and ethical engagement. Participants were recruited using a stratified random sampling strategy, which stratified for active online faculty.

Utilizing $\mathrm{G}^{*}$ Power software, Version 3.1.9.7, an a prior analysis was performed to determine the needed sample for power purposes. Using a 0.3 medium effect size, 0.80 power, 
and 0.05 significance, the analysis indicated a desired sample of 84 participants (Cohen, 1988). From the list of active online faculty at the university, a research center representative at the university sent the recruitment email to approximately 2000 online faculty members. SurveyMonkey was used to collect the survey data.

\section{Instruments}

The researchers used 39 items from the 72-item version of Value in Action Classification of Virtues and Strengths (VIA-72) and the 10-item Santa Clara Ethics Scale (SCES). An explanation of both surveys follows below.

Value in Action Classification of Virtues and Strengths (VIA-72) To gather data on online faculty members' intellectual, interpersonal, and emotional character strengths, the researchers employed several subtests of the VIA-72 assessment. The 72 items measured the 24 character strengths respectively, and each character strength had three corresponding questions in the survey. This study focused on intellectual strengths (creativity, curiosity, love of learning, and appreciation of beauty and excellence), interpersonal strengths (kindness, love, leadership, teamwork, and humor), and emotional strengths (bravery, hope, selfregulation, and zest). Therefore, only the specific items used to measure those strengths from the VIA-72 were provided in the online survey.

All versions of the VIA-IS seek to measure the 24 respective strengths (Peterson \& Seligman, 2004). Since this study only focused on intellectual, interpersonal, and emotional strengths, the survey consisted of only a total of 39 items related to the character strengths of interest for the participants. Each item was a descriptive statement; participants were asked to rate how well the statements described them, with options ranging from 1 (very much unlike me) to 5 (very much like me). The score for each strength was the mean of the summed scores of the three corresponding items in the VIA-72 (Peterson \& Seligman, 2004).

Santa Clara Ethics Scale (SCES) To examine online faculty members' ethical engagement, Plante and McCreadie's (2019a) SCES was used. This scale has 10 items; we used it to measure ethical engagement through a virtue approach, highlighting respect, responsibility, integrity, competence, and concerns for others. Similar to the VIA-72, each item offered a descriptive statement; each participant was asked to rate how well the statements described them, with options ranging from 1 (strongly disagree) to 4 (strongly agree). The score of ethical engagement was the sum score of the 10 items (Plante \& McCreadie, 2019a).

\section{Data Analysis}

We downloaded the raw data from the online survey development software and uploaded it into data analysis software, where we cleaned and error-checked the data. We performed statistical analyses using SPSS version 26. wWe first performed descriptive statistics, including mean, standard deviation, and skewness. Afterwards, we performed correlation analyses using Pearson Correlation to assess the relationship between the three types of character strengths and ethical engagement. 
Table 3 Descriptive Statistics

\begin{tabular}{lcccllll}
\hline Variable & $N$ & $M$ & $S D$ & Skewness & Range & Minimum & Maximum \\
\hline Intellectual Strengths & 341 & 4.17 & .51 & -.646 & 2.34 & 2.67 & 5 \\
Interpersonal Strengths & 341 & 3.86 & .53 & -.234 & 2.92 & 2.08 & 5 \\
Emotional Strengths & 341 & 4.25 & .48 & -.655 & 2.87 & 2.13 & 5 \\
Ethical Engagement & 341 & 36.70 & 2.77 & -.801 & 13 & 27 & 40 \\
\hline
\end{tabular}

Skewness exceeds normality range \pm 1.0

\section{Results}

\section{Descriptive Statistics}

Table 3 presents descriptive information about intellectual strengths $(M=4.17$, $S D=0.51)$, interpersonal strengths $(M=3.86, S D=0.53)$, emotional strengths $(M=4.25$, $S D=0.48)$, and ethical engagement $(M=36.70, S D=2.77)$ collected from the sample. Reliability coefficients were also computed to ensure data reliability. Table 4 presents the Cronbach's alphas for the subscale scores of the character strengths. All alpha values were greater than 0.70 , which indicates good reliability.

\section{Addressing the Research Questions}

The results of Pearson Correlation analyses are presented in Table 5, based on the research questions. We found statistically significant relationships between ethical engagement and the following variables: intellectual character strengths $(r=0.368, p<0.05)$, interpersonal character strengths $(r=0.416, p<0.05)$, and emotional character strengths $(r=0.528$, $p<0.05$ ). For Research Question 1, there was a weak positive correlation between intellectual character strengths (creativity, curiosity, love of learning, and appreciation of beauty and excellence) and ethical engagement in online higher education faculty. For Research Question 2, there was a moderate positive correlation between interpersonal character strengths (kindness, love, leadership, teamwork, and humor) and ethical engagement in online higher education faculty. Finally, for Research Question 3, there was a moderate positive correlation between emotional character strengths (bravery, hope, self-regulation, and zest) and ethical engagement in online higher education faculty. We also computed coefficients of determination to illustrate the level ethical engagement can be explained by its relationship to the three types of character strengths. Intellectual strengths accounted for $13.5 \%$ of the variation in ethical engagement with adjusted $\mathrm{R}^{2}=13.3 \%$. Interpersonal strengths accounted for $17.3 \%$ of the variation in ethical engagement with adjusted $\mathrm{R}^{2}=17.1 \%$. Emotional strengths accounted for $27.9 \%$ of the variation in ethical engagement with adjusted $\mathrm{R}^{2}=27.7 \%$.

Table 4 Reliability of Character Strengths and Ethical Engagement Scores

\begin{tabular}{lllll}
\hline Variable & Intellectual Strengths & Interpersonal Strengths & Emotional Strengths & Ethical Engagement \\
\hline Sample & .839 & .867 & .839 & .739 \\
\hline
\end{tabular}

Reliability coefficients of 0.70 or greater indicate acceptable reliability 
Table 5 Pearson Correlation Coefficients for Character Strengths and Ethical Engagement Scores

\begin{tabular}{|c|c|c|c|c|c|c|c|}
\hline & & & & $\begin{array}{l}\text { Intellectual } \\
\text { Strengths }\end{array}$ & $\begin{array}{l}\text { Interpersonal } \\
\text { Strengths }\end{array}$ & $\begin{array}{l}\text { Emotional } \\
\text { Strengths }\end{array}$ & $\begin{array}{l}\text { Ethical } \\
\text { Engagement }\end{array}$ \\
\hline \multirow[t]{12}{*}{ Pearson's r } & \multirow[t]{3}{*}{$\begin{array}{r}\text { Intellectual } \\
\text { Strengths }\end{array}$} & $\begin{array}{l}\text { Correlation } \\
\text { Coefficient }\end{array}$ & 1.000 & $.532^{* * *}$ & $.486^{* *}$ & $.368^{* *}$ & \\
\hline & & Sig. (2-tailed) & & .000 & .000 & .000 & \\
\hline & & $\mathrm{N}$ & 341 & 341 & 341 & 341 & \\
\hline & \multirow[t]{3}{*}{$\begin{array}{l}\text { Interpersonal } \\
\text { Strengths }\end{array}$} & $\begin{array}{l}\text { Correlation } \\
\text { Coefficient }\end{array}$ & $.486^{* *}$ & 1.000 & $.638^{* * *}$ & $.416^{* *}$ & \\
\hline & & Sig. (2-tailed) & .000 & & .000 & .000 & \\
\hline & & $\mathrm{N}$ & 341 & 341 & 341 & 341 & \\
\hline & \multirow[t]{3}{*}{$\begin{array}{l}\text { Emotional } \\
\text { Strengths }\end{array}$} & $\begin{array}{l}\text { Correlation } \\
\text { Coefficient }\end{array}$ & $.532^{* * *}$ & $.638^{* * *}$ & 1.000 & $.528^{* *}$ & \\
\hline & & Sig. (2-tailed) & .000 & .000 & & .000 & \\
\hline & & $\mathrm{N}$ & 341 & 341 & 341 & 341 & \\
\hline & \multirow[t]{3}{*}{$\begin{array}{l}\text { Ethical } \\
\text { Engagement }\end{array}$} & $\begin{array}{l}\text { Correlation } \\
\text { Coefficient }\end{array}$ & $.368^{* * *}$ & $.416^{* * *}$ & $.528^{* * *}$ & 1.000 & \\
\hline & & Sig. (2-tailed) & .000 & .000 & .000 & & \\
\hline & & $\mathrm{N}$ & 341 & 341 & 341 & 357 & \\
\hline
\end{tabular}

**Correlation is significant at the 0.01 level (2-tailed)

\section{Discussion and Conclusions}

This study showed emotional strengths and interpersonal strengths were moderately related to ethical engagement, whereas intellectual strengths were weakly related to ethical engagement. Overall, these findings support the character strengths model by showing character strengths are related to ethical behavior. To begin with, the findings demonstrated that emotional strengths were associated with online faculty's ethical engagement. Emotional strengths (bravery, hope, self-regulation, and zest) enable their possessors to approach emotional experience openly, optimistically, and enthusiastically. They allow one to be more prepared to endure stressful situations effectively and ethically. This may explain why emotional character strengths were associated with ethical engagement. When faced with stressful situations at work, such as heavy workload and conflicts with students, online faculty with emotional strengths may be better equipped to manage stress, adhere to high ethical standards, and behave ethically in regard to their teaching practices.

Emotional strengths also share two character strengths with the character strengths of courage from the six-virtue classification, specifically, bravery and zest. Researchers have theorized that the character strengths of courage (bravery, perseverance, integrity, and zest) carry the most moral weight among all the 24 character strengths (Han, 2019). They empower faculty with the will to achieve goals even in the face of opposition (McGovern, 2011; McGovern $\&$ Miller, 2008). Without the character strengths of courage, faculty may know the ethical action required in the specific circumstance but lack the will to execute and follow through with the ethical action. For example, they may not address online students' hostile discussion tendencies to avoid the risk of inconvenience or confrontation even if they know addressing such tendencies is the necessary ethical action. Emotional strengths' inclusion of the two character strengths, bravery and zest, from the character strengths of courage in the six-virtue classification may be related to the research finding. 
Additionally, we found that interpersonal strengths (kindness, love, leadership, teamwork, and humor) were moderately related to ethical engagement. Interpersonal strengths concern the capacity of handling and sustaining social interaction with others positively. Being ethical often involves the consideration of others and prosocial behaviors (Plante, 2004). This relationship may explain why individuals with a higher degree of interpersonal strengths are more likely to be ethically engaged. Communication in the online higher education classroom usually takes place in the written form (Lapadat, 2002). Online faculty members with interpersonal strengths may be more prepared to initiate and sustain positive interactions with students in the written format. This characteristic may be useful to establishing trusting relationships between online faculty and students, which have been found to protect against unethicality (Tsui \& Ngo, 2016). Thus, online faculty members with interpersonal strengths are better positioned to establish positive and trusting relationships with students. They may be less likely to demonstrate unethical behavior.

Nonetheless, it is noteworthy that intellectual strengths (creativity, curiosity, love of learning, and appreciation of beauty and excellence) were only weakly related to ethical engagement. As McGovern (2012) noted, intellectual strengths support individuals to "do the heavy lifting" (p. 74). Intellectual strengths facilitate knowledge acquisition and problem-solving. The limited relationship between intellectual strengths and ethical engagement may suggest that despite the necessity of knowledge and problem-solving ability in ethical engagement, intellectual strengths alone are insufficient in helping individuals to behave ethically. Individuals can be intelligent but use their intelligence toward unethical or selfish ends (Sternberg, 2009). Historical moral exemplars generally exhibit both intellectual strengths and other types of strengths, such as interpersonal strengths (Sternberg, 2009). Some examples of these historical moral exemplars include Mahatma Gandhi, Mother Teresa, and Nelson Mandela (Sternberg, 2009).

Finally, the findings of the study are relevant to online higher education because of its unique challenges for faculty, such as changes in faculty role, increased preparation time, communication barriers, as well as learner readiness and engagement (Kebritchi et al., 2017). The findings are also especially valuable in the prevalence of online higher education resulted from the COVID-19 pandemic, as more faculty members transition to teaching online. The work of a teacher involves the use of intellectual, interpersonal, and emotional skills. Because online faculty are teachers, those with intellectual, interpersonal, and emotional strengths are better equipped to engage in effective online teaching practices. The study's findings about the relationships between these strengths and ethical engagement affirm the importance of these strengths in ethical behavior. As these intellectual, interpersonal, and emotional strengths become manifested in online faculty's cognition, emotion, and action, those who demonstrate high levels of character strengths may demonstrate a high level of ethical engagement. Faculty members' ethical behavior is influential to their teaching practices (Ozcan et al., 2013). As a result, they may be less likely to behave unethically and more likely to utilize effective teaching methods in the online higher education classroom.

\section{Implications, Limitations, and Future Research}

The current study's findings have several implications for online higher education. It is necessary for online faculty members to employ ethical and effective teaching practices when building online learning communities, so that students receive high-quality learning experiences (Sethy, 2018). Character strengths are trainable personal characteristics (Harzer \& Ruch, 2015). Recognized as effective tools that influence teaching practices, 
character strengths, especially intellectual, emotional, and interpersonal strengths, may be integrated into faculty development to facilitate sustainable personal and professional growth (McGovern, 2011). Furthermore, since character strengths predispose online faculty to teach effectively, these character strengths may be used in hiring and performance evaluation.

This study has several limitations. First, the study is limited to the sample of online faculty at a four-year university in the Midwest of the United States. The generalizability of the findings is limited. Next, although we used valid and reliable instruments to measure character strengths and ethical engagement, these instruments are self-reported measures. Ethical engagement measured by the SCES significantly correlated with social desirability (Plante \& McCreadie, 2019a). A similar concern might be present in the VIA-IS. As such, the study is limited by possible self-reporting bias, which means there could be a difference between self-reported and true values of character strengths and ethical engagement. In addition, we did not collect other data to examine possible factors that may have affected the results of the study. Lastly, we intended for this study to provide implications on teaching practices, but the study did not examine components related to online teaching effectiveness.

Based on the findings and limitations of this study, we make a few recommendations for future research. First, when examining the relationship between character strengths and ethical engagement, we adopted Pearson and Seligman's five-factor classification of character strengths instead of their original six-virtue classification. Future researchers may examine this relationship using the six-virtue classification of the character strengths (e.g., the relationship between the character strengths of courage and ethical engagement). They may also examine the relationships between individual character strengths and ethical engagement (e.g., the relationship between bravery and ethical engagement). Second, future researchers should minimize the effect of social desirability.

Third, to further explore the role of character strengths in ethical engagement, qualitative methods may be helpful. For instance, future researchers may explore how online faculty utilize their interpersonal and emotional strengths to engage in ethical behavior in their online teaching work. Finally, although this study sampled online faculty with respect to their character strengths and ethical engagement, it did not examine components about effective online teaching. Therefore, there is a need for future empirical studies to examine the relationships concerning character strengths, ethics (such as ethical engagement), and specific teaching practices in online faculty. Understanding these relationships may help online faculty members and higher education institutes gain important insights into online teaching practices. It will also provide the scholarly community with a deeper understanding of what might contribute to online faculty's ethical behavior and effective online teaching practices.

Authors' Contributions All authors contributed to the study's conception and design. Material preparation, data collection, and analysis were performed by the first and second authors. The first author wrote the first draft of the manuscript, and all authors commented on that and all subsequent versions of the manuscript. All authors read and approved the final manuscript.

Funding The authors declare that they received no funding for this study.

Availability of Data and Material The datasets generated during and/or analyzed during the current study are available from the corresponding author on reasonable request. 


\section{Declarations}

Conflicts of Interest The authors declare that they have no conflict of interest.

\section{References}

Aldosemani, T. I. (2020). Towards ethically responsive online education: Variables and strategies from educators' perspective. Journal of Education and Learning, 9(1), 79-86. https://doi.org/10.5539/jel.v9n1p79

Alt, D., \& Itzkovich, Y. (2015). Assessing the connection between students' justice experience and perceptions of faculty incivility in higher education. Journal of Academic Ethics, 13(2), 121-134. https://doi. org/10.1007/s10805-015-9232-8

Alt, D., \& Itzkovich, Y. (2016). Adjustment to college and perceptions of faculty incivility. Current Psychology, 35(4), 657-666. https://doi.org/10.1007/s12144-015-9334-x

Alt, D., \& Itzkovich, Y. (2019). The connection between perceived constructivist learning environments and faculty uncivil authoritarian behaviors. Higher Education, 77(3), 437-454. https://doi.org/10.1007/ s10734-018-0281-y

American Association of University Professors. (2009). Statement on professional ethics. https://www. aaup.org/report/statement-professional-ethics

Asamoah, M. K. (2019) TPACKEA model for teaching and students' learning. Journal of Academic Ethics, 17(4), 401-421. https://doi.org/10.1007/s10805-019-09326-4

Ayers, W. (2001). To teach: The journey of a teacher. Teachers College Press.

Bretag, T., \& Green, M. (2014). The role of virtue ethics principles in academic integrity breach decision-making. Journal of Academic Ethics, 12(3), 165-177. https://doi.org/10.1007/ s10805-014-9209-z

Carrillo, A., Crittenden, C., \& Garland, T. (2019). Faculty perceptions of consensual sexual relationships between university faculty and students. Journal of Academic Ethics, 17(4), 331-343. https:// doi.org/10.1007/s10805-019-09337-1

Cohen, J. (1988). Statistical power analysis for the behavioral sciences (2nd ed.). Psychology Press Taylor Francis Group.

Corlett, J. A. (2014). The role of philosophy in academic ethics. Journal of Academic Ethics, 12(1), 1-14. https://doi.org/10.1007/s10805-014-9201-7

Crossan, M., Mazutis, D., \& Seijts, G. (2013). In search of virtue: The role of virtues, values and character strengths in ethical decision making. Journal of Business Ethics, 113(4), 567-581. https://doi. org/10.1007/s 10551-013-1680-8

Duan, W., \& Ho, S. M. (2018). Does being mindful of your character strengths enhance psychological wellbeing? A longitudinal mediation analysis. Journal of Happiness Studies, 19(4), 1045-1066. https://doi.org/10.1007/s10902-017-9864-Z

Eisenschmidt, E., Kuusisto, E., Poom-Valickis, K., \& Tirri, K. (2019). Virtues that create purpose for ethical leadership: Exemplary principals from Estonia and Finland. Journal of Beliefs \& Values, 40(4), 433-446. https://doi.org/10.1080/13617672.2019.1618152

Galikyan, I., \& Admiraal, W. (2019). Students' engagement in asynchronous online discussion: The relationship between cognitive presence, learner prominence, and academic performance. The Internet and Higher Education, 43, 100692. https://doi.org/10.1016/j.iheduc.2019.100692

Ghosh, K. (2016). Virtue in school leadership: Conceptualization and scale development grounded in Aristotelian and Confucian typology. Journal of Academic Ethics, 14(3), 243-261. https://doi.org/ $10.1007 / \mathrm{s} 10805-016-9259-5$

Han, H. (2019). The VIA inventory of strengths, positive youth development, and moral education. The Journal of Positive Psychology, 14(1), 32-40. https://doi.org/10.1080/17439760.2018.1528378

Harzer, C., \& Ruch, W. (2015). The relationships of character strengths with coping, work-related stress, and job satisfaction. Frontiers in Psychology, 6, 165. https://doi.org/10.3389/fpsyg.2015.00165

Henning, M., Alyami, M., Melyani, Z., Alyami, H., \& Al Mansour, A. (2020). Development of the crosscultural academic integrity questionnaire-version 3 (CCAIQ-3). Journal of Academic Ethics, 18(1), 35-53. https://doi.org/10.1007/s10805-019-09350-4

Höfer, S., Gander, F., Höge, T., \& Ruch, W. (2020). Character strengths, well-being, and health in educational and vocational settings. Applied Research in Quality of Life, 15(2), 301-306. https://doi.org/ 10.1007/s11482-018-9688-y 
Jamil, R., Mohammad, J., \& Ramu, M. (2019). Antecedents of unethical behaviour intention: Empirical study in public universities in Malaysian context. Journal of Academic Ethics, 17(1), 95-110. https://doi.org/10.1007/s10805-018-9312-7

Kebritchi, M., Lipschuetz, A., \& Santiague, L. (2017). Issues and challenges for teaching successful online courses in higher education: A literature review. Journal of Educational Technology Systems, 46(1), 4-29. https://doi.org/10.1177/0047239516661713

Lapadat, J. C. (2002). Written interaction: A key component in online learning. Journal of ComputerMediated Communication, 7(4). https://doi.org/10.1111/j.1083-6101.2002.tb00158.x

Martin, F., Ritzhaupt, A., Kumar, S., \& Budhrani, K. (2019). Award-winning faculty online teaching practices: Course design, assessment and evaluation, and facilitation. The Internet and Higher Education, 42, 34-43. https://doi.org/10.1016/j.iheduc.2019.04.001

Martin, F., Wang, C., \& Sadaf, A. (2018). Student perception of helpfulness of facilitation strategies that enhance instructor presence, connectedness, engagement and learning in online courses. The Internet and Higher Education, 37, 52-65. https://doi.org/10.1016/j.iheduc.2018.01.003

Martínez-Martí, M. L., \& Ruch, W. (2017). Character strengths predict resilience over and above positive affect, self-efficacy, optimism, social support, self-esteem, and life satisfaction. The Journal of Positive Psychology, 12(2), 110-119. https://doi.org/10.1080/17439760.2016.1163403

McGovern, T. V. (2011). Virtues and character strengths for sustainable faculty development. The Journal of Positive Psychology, 6(6), 446-450. https://doi.org/10.1080/17439760.2011.634822

McGovern, T. V. (2012). Faculty virtues and character strengths: Reflective exercises for sustained renewal. Society for the Teaching of Psychology Website: http://teachpsych.org/ebooks/fvcs2012/ index.php

McGovern, T. V., \& Miller, S. L. (2008). Integrating teacher behaviors with character strengths and virtues for faculty development. Teaching of Psychology, 35(4), 278-285. https://doi.org/10.1080/ 00986280802374609

McGrath, R. E. (2015a). Character strengths in 75 nations: An update. The Journal of Positive Psychology, 10(1), 41-52. https://doi.org/10.1080/17439760.2014.888580

McGrath, R. E. (2015b). Integrating psychological and cultural perspectives on virtue: The hierarchical structure of character strengths. The Journal of Positive Psychology, 10(5), 407-424. https://doi. org/10.1080/17439760.2014.994222

McNeill, J., Dunemn, K., Einhellig, K. S., \& Clukey, L. (2016). Exploring nursing student and faculty perceptions of incivility in the online learning environment. Journal of Nursing Education and Practice, 7(5), 45-54. https://doi.org/10.5430/jnep.v7n5p45

Mohammadipour, M., Hasanvand, S., Goudarzi, F., Ebrahimzadeh, F., \& Pournia, Y. (2018). The level and frequency of faculty incivility as perceived by nursing students of Lorestan University of Medical Sciences. Journal of Medicine and Life, 11(4), 334-342. https://doi.org/10.25122/ jml-2018-0055

Moore, E. (2020). Inconsistent responses to notifications of suspected plagiarism in Finnish higher education. Journal of Academic Ethics, 18, 1-16. https://doi.org/10.1007/s10805-019-09354-0

Najderska, M., \& Cieciuch, J. (2018). The structure of character strengths: Variable- and person-centered approaches. Frontiers in Psychology, 9, 153. https://doi.org/10.3389/fpsyg.2018.00153

Or, J. (2020). The relationships between character strengths and ethical engagement in public sector human services professionals (Order No. 28150739) [Doctoral dissertation, Grand Canyon University]. ProQuest Dissertations \& Theses. (2457926570). https://www.proquest.com/docview/24579 26570/5D3514D040441E4PQ/1

Ouyang, F., \& Scharber, C. (2017). The influences of an experienced instructor's discussion design and facilitation on an online learning community development: A social network analysis study. The Internet and Higher Education, 35, 34-47. https://doi.org/10.1016/j.iheduc.2017.07.002

Ozcan, K., Balyer, A., \& Servi, T. (2013). Faculty members' ethical behaviors: A survey based on students' perceptions at universities in Turkey. International Education Studies, 6(3), 129-142. https:// doi.org/10.5539/ies.v6n3p129

Palanski, M. E., Cullen, K. L., Gentry, W. A., \& Nichols, C. M. (2015). Virtuous leadership: Exploring the effects of leader courage and behavioral integrity on leader performance and image. Journal of Business Ethics, 132(2), 297-310. https://doi.org/10.1007/s10551-014-2317-2

Pau, A., Thangarajoo, S., Samuel, V. P., Wong, L. C., Wong, P. F., Matizha, P., \& Nadarajah, V. D. (2019). Development and validation of a Script Concordance Test (SCT) to evaluate ethical reasoning ability among first and fifth year students in a medical school. Journal of Academic Ethics, 17(2), 193-204. https://doi.org/10.1007/s10805-019-09327-3

Peterson, C., \& Seligman, M. E. P. (2004). Character strengths and virtues: A handbook and classification. Oxford University Press. 
Plante, T. G. (2004). Do the right thing: Living ethically in an unethical world. New Harbinger Publications.

Plante, T. G., \& McCreadie, A. (2019a). The Santa Clara ethics scale. Pastoral Psychology, 68(3), 321329. https://doi.org/10.1007/s11089-019-00861-w

Plante, T. G., \& McCreadie, A. (2019b). Further developments of the Santa Clara ethics questionnaire. Pastoral Psychology, 68, 681-686. https://doi.org/10.1007/s11089-019-00882-5

Plante, T. G., \& Plante, L. G. (2017). Graduating with honor: Best practices to promote ethics development in college students. Praeger/ABC-CLIO.

Roberts, R. C. (2016). Are some of the things faculty do to maximize their student evaluation of teachers scores unethical? Journal of Academic Ethics, 14(2), 133-148. https://doi.org/10.1007/ s10805-015-9247-1

Sethy, S. S. (2018). Academic ethics: Teaching profession and teacher professionalism in higher education settings. Journal of Academic Ethics, 16(4), 287-299. https://doi.org/10.1007/ s10805-018-9313-6

Simpson, E. (2003). The faculty of the future. Journal of Academic Ethics, 1(1), 49-58. https://doi.org/ 10.1023/A:1025425807240

Sternberg, R. J. (2009). We need to teach for ethical conduct. The Educational Forum, 73(3), 190-198. https://doi.org/10.1080/00131720902991228

Sosik, J. J., Chun, J. U., Ete, Z., Arenas, F. J., \& Scherer, J. A. (2019). Self-control puts character into action: Examining how leader character strengths and ethical leadership relate to leader outcomes. Journal of Business Ethics., 160(3), 765-781. https://doi.org/10.1007/s10551-018-3908-0

Symbaluk, D. G., \& Howell, A. J. (2018). Character strengths of teaching and research award-winning professors. Journal on Excellence in College Teaching, 29(1), 5-26.

Tagne, A. M., Cassina, N., Furgiuele, A., Storelli, E., Cosentino, M., \& Marino, F. (2020). Perceptions and attitudes about research integrity and misconduct: A Survey among young biomedical researchers in Italy. Journal of Academic Ethics, 18, 193-205.

Tauginienè, L. (2016). Embedding academic integrity in public universities. Journal of Academic Ethics, 14(4), 327-344. https://doi.org/10.1007/s10805-016-9268-4

Thun, B., \& Kelloway, E. K. (2011). Virtuous leaders: Assessing character strengths in the workplace. Canadian Journal of Administrative Sciences/revue Canadienne Des Sciences De L'administration, 28(3), 270-283. https://doi.org/10.1002/cjas.216

Tsui, A. P., \& Ngo, H. Y. (2016). Social predictors of business student cheating behaviour in Chinese societies. Journal of Academic Ethics, 14(4), 281-296. https://doi.org/10.1007/s10805-016-9266-6

Wang, M., Cheng, B., Chen, J., Mercer, N., \& Kirschner, P. A. (2017). The use of web-based collaborative concept mapping to support group learning and interaction in an online environment. The Internet and Higher Education, 34, 28-40. https://doi.org/10.1016/j.iheduc.2017.04.003

Wotto, M. (2020). The future high education distance learning in Canada, the United States, and France: Insights from before COVID-19 secondary data analysis. Journal of Educational Technology Systems, 49(2), 262-281. https://doi.org/10.1177/0047239520940624

Publisher's Note Springer Nature remains neutral with regard to jurisdictional claims in published maps and institutional affiliations. 